\title{
DISTRIBUSI MIKROPLASTIK PADA SEDIMEN DI PERAIRAN TELUK KENDARI
}

\section{Distribution Microplastic at Sediment in the Kendari Bay}

\author{
Aswan Akbardin Layn ${ }^{1}$, Emiyarti $^{2}$, Ira $^{3}$ \\ ${ }^{1}$ Mahasiswa Ilmu Kelautan \\ Fakultas Perikanan dan Ilmu Kelautan Universitas Halu Oleo \\ Jl. HEA Mokodompit Kampus Bumi Tridharma Anduonohu Kendari 93232 \\ ${ }^{2}$ Surel: emiyarti@ymail.com \\ ${ }^{3}$ Surel: bahari_00@yahoo.co.id
}

\begin{abstract}
Abstrak
Mikroplastik merupakan plastik yang berukuran kurang dari $\leq 5 \mathrm{~mm}$. Mirkoplastik yang terdegradasi dapat ditemukan di sedimen perairan. Penelitian ini bertujuan untuk mengatahui jenis-jenis mikroplastik dan nilai kelimpahan mikroplastik yang mengendap pada sedimen di Perairan Teluk Kendari. Penelitian ini telah dilaksanakan pada bulan Januari 2019 sampai dengan Juli 2019. Pengamatan sampel sedimen dilakukan di Laboratorium Pengujian Fakultas Perikanan dan Ilmu Kelautan, Universiats Halu Oleo. Pengamatan di lakukan dengan beberapa tahap yaitu tahap pegeringan, pengurangan volume, pemisahan densitas dan penghitungan dengan menggunakan mikroskop. Hasil penelitian menunjukan bahwa jenis mikroplastik yang ditemukan ada tiga jenis yaitu tipe fragmen, film dan fiber. Mikroplastik yang paling banyak ditemukan pada sedimen berdasarkan jenis pada setiap stasiunnya adalah jenis film dengan kelimpahan 2 partikel/gr sedimen sedangkan kelimpahan terendah adalah jenis fiber yaitu 0.07 partikel/gr sedimen. Dengan persentase jenis kelimpahan mikroplastik paling tinggi secara keseluruhan yaitu fragmen (52\%), film (42\%) dan fiber (6\%). Keberadaan mikroplastik pada sedimen menjadi perhatian untuk mengelola perairan serta potensi perikanan dan kelautan di Teluk Kendari.
\end{abstract}

Kata Kunci: Mikroplastik, Sedimen, Teluk Kendari.

\begin{abstract}
Microplastic is a plastic less than $\mathrm{mm} 5 \mathrm{~mm}$ in size. Micoploplastics who degrading can be found in aquatic sediments. This study aimed to determine the types of microplastic and the abundance values of microplastic that settled on sediments in Kendari Bay. This research was carried out on January 2019 until July 2019. The observation of sediment samples was conducted at the Testing Laboratory of the Faculty of Fisheries and Marine Sciences, Halu Oleo University. The observations were made in several stages, namely drying stage, volume reduction, density separation and calculation using microscope. The results showed that there were three types of microplastic types, namely fragment, film and fiber types. The microplastict we found on sediment was film with abudance 2 particles/gr sediment, while the lowest abudance was fiber with 0.07 particles/gr sediment. The highest abudance was fragmen (52\%), film $42(\%)$ and fiber $6(\%)$. The presence of microplastics at sediment is a concern for managing water with fisheries and marine potential in Kendari Bay.
\end{abstract}

Keywords: Microplastict, Sediment, Kendari Bay.

\section{Pendahuluan}

Mikroplastik merupakan plastik yang berukuran kecil $\leq 5 \mathrm{~mm}$. Mikroplastik juga merupakan salah satu jenis limbah yang paling berbahaya jika masuk kelingkungan perairan. Keberadaan miroplastik dalam kelingkungan perairan disebabkan oleh potongan-potongan plastik yang lebih besar yang secara mekanis terurai melalui aksi gelombang, penggilingan pasir dan proses lainnya. boucher (2009), juga mengatakan bahwa kerusakan aksi mekanis dari plastik semakin diperburuk oleh degradasi akibat sinar matahari (fotodegradasi), degradasi akibat suhu perairan (degradasi termal), dan degradasi akibat mahluk hidup (biodegradasi) hal inilah yang menyebabkan banyak ditemukan mikroplastik pada perairan.
Jenis mikroplastik yang umum masuk kedalam perairan diantaranya ialah : fragmen, fiber, dan film (Sari et al., 2015). Selain pada permukaan air, mikroplastik juga ditemukan pada dasar perairan atau sedimen. Berdasarkan penelitian yang dilakukan Hidalgo-Ruz (2012) dari hasil review tersebut menunjukkan bahwa nilai konsentrasi mikroplastik tertinggi ditemukan pada sedimen dibandingkan pada bagian permukaan air (Chubarenko et al. 2016). Adanya keberadaan mikroplastik di dasar sedimen dipengaruhi oleh gaya gravitasi dan besaran densitas plastik yang lebih tinggi dibandingkan densitas air menyebabkan plastik tenggelam dan terakumulasi disedimen (Woodall et al. 2015). 
Masuknya mikroplastik dalam perairan terkhusus pada sedimen akan sangat mempengaruhi siklus rantai makanan biota yang ada. Dampak mikroplastik pada biota di perairan yaitu berpotensi menyebabkan kerusakan bagi biota. Masuknya mikroplastik ke dalam tubuh biota dapat merusak fungsi ada organ - organ seperti: saluran pencernaan, mengurangi tingkat pertumbuhan, menghambat produksi enzim, menurunkan kadar hormon steroid, mempengaruhi reproduksi, dan dapat menyebabkan paparan aditif plastik lebih besar sifat toksik (Wright et al., 2013). Hal ini menandakan bahwa mikroplastik berpotensi mengancam lebih serius dibandingkan dengan material plastik yang berukuran besar. Banyaknya plastik yang ada di perairan dipengaruhi oleh aktifitas pemukiman yang ada disekitar sungai/perairan seperti halnya yang ada disekitar Perairan Teluk Kendari.

Perairan Teluk Kendari merupakan salah satu perairan yang menjadi titik akhir beberapa daerah aliran sungai yang bermuara ke laut. Dari 13 sungai yang bermuara ke Teluk Kendari, Daerah Aliran Sungai (DAS) Wanggu merupakan aliran sungai yang memberikan kontribusi paling besar terhadap Perairan Teluk Kendari dibandingkan dengan sungai lainnya (Putra, 2017). Seiring dengan bertambahnya populasi masyarakat di wilayah tersebut, banyak aktifitas yang terjadi di wilayah pesisir dan Perairan Teluk Kendari, seperti bongkar muat kapal di pelabuhan, penangkapan ikan dan aktifitas rumah tangga. Sehingga dikhawatirkan terjadi pembuangan di wilayah pemukiman dan tepi sungai yang mengarah ke laut.

Disamping itu, belum adanya informasi awal tentang mikroplastik merupakan salah satu kendala mengelola potensi perikanan dan kelautan yang berbasis ramah lingkungan. Berdasarkan hal tersebut, perlu adanya penelitian untuk mengetahui distribusi mikroplastik pada sedimen di Perairan Teluk Kendari. Tujuan dari penelitian ini adalah untuk mengetahui jenis dan kelimpahan mikroplastik yang mengendap pada sedimen di Perairan Teluk Kendari.

\section{Bahan dan Metode}

Penelitian ini akan dilaksanakan pada bulan Januari-Juli 2019. Lokasi pengambilan sampel sedimen pada penelitian ini dilakukan di Perairan Teluk Kendari, Provinsi Sulawesi Tenggara. Analisis sampel sedimen dilakukan di Laboratorium Pengujian Fakultas Perikanan dan Ilmu Kelautan, Universitas Halu Oleo, Kendari.

Adapun 4 titik stasiun lokasi pengambilan sampel pada penelitian ini adalah sebagai berikut:
a. ST 1. Muara Sungai Wanggu ( $3^{0} 58^{\prime} 39,4$ '"LS $-122^{0} 32^{\prime} 01,1$ 'BT)
b. ST 2. Pemukiman Penduduk (03058'12,6'LS-122033'52,3'BT)
c. ST 3. Pelabuhan Nusantra $\left(03^{0} 58^{\prime} 26,1^{\prime \prime} L S-\right.$ $\left.122^{\circ} 34^{\prime} 53,5^{\prime \prime} \mathrm{BT}\right)$
d. ST 4. PPS Kendari $\left(03^{0} 58^{\prime} 49,8^{\prime \prime}\right.$ LS- $122^{0} 34^{\prime} 22,9^{\prime \prime} \mathrm{BT}$ )

Alat yang digunakan pada penelitian ini yaitu layangan arus, thermometer, kertas sampel, Coolbox, Pipa paralon, kertas label, oven, mikroskop, gelas beaker, batang pengaduk, pipet ukur, kaca preparat, timbangan analitik, saringan bertingkat dan peralatan penunjang lainnya. Sedangkan bahan yang digunnakan yaitu sampel sedimen dan larutan $\mathrm{NaCl}$ Jenuh.

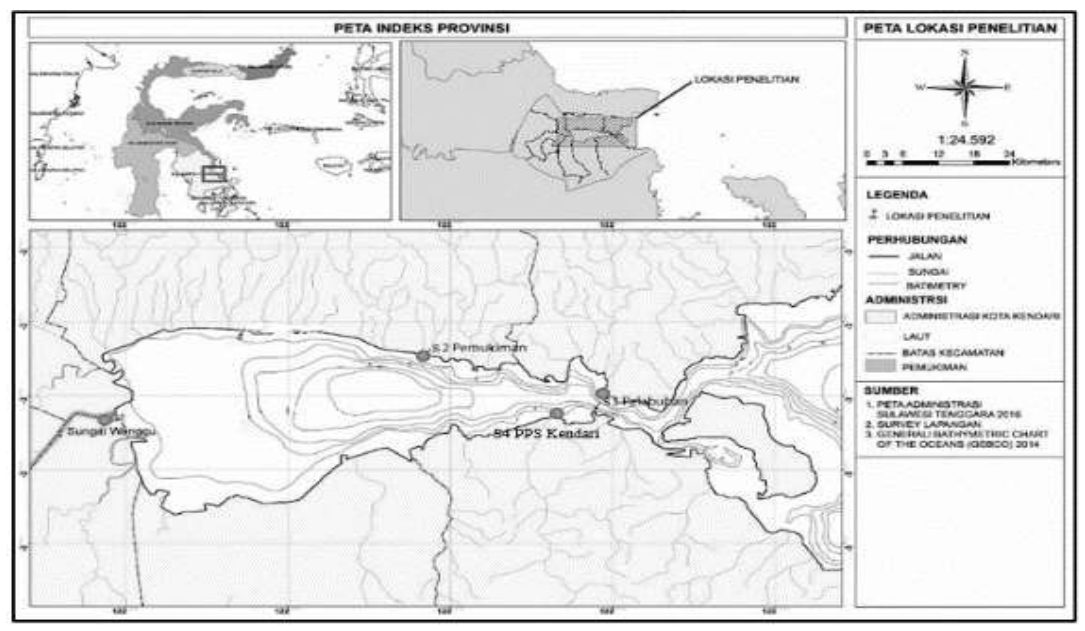

Gambar 1. Peta Lokasi Penelitian 
Prosedur penelitian meliputi beberapa tahapan diantaranya yaitu: survei perdahuluan, penentuan stasiun penelitian, pengambilan sampel sedimen, dan menganalisis sampel sedimen di Laboratorium.

Survei pendahuluan dilakukan di Perairan Teluk Kendari, mulai dari muara sungai hingga mulut teluk. Penentuan stasiun pengambilan sampel ditentukan dengan menggunakan metode purposive sampling yaitu penentuan stasiun dengan berdasarkan lokasi atau daerah yang memiliki aktifitas yang diduga sebagai potensi sumber limbah plastik pada daerah sekitar Teluk Kendari.

Pengambilan sampel sedimen dilakukan disetiap stasiun dengan menggunakan pipa paralon berukuran 4 inchi dengan kedalaman 0$10 \mathrm{~cm}$. Sampel sedimen kemudian dimasukan pada kantong plastik dan diberi kode menggunakan kertas label. Seluruh sampel sedimen untuk semua titik stasiun lokasi disimpan pada coolbox. Pengambilan sampel sedimen dilakukan dengan pengulangan sebanyak dua kali pada setiap stasiun.

Adapun tahapan analisis sample sedimen dapat dilihat berdasarkan langkah-langkah berikut

a. Pengeringan

Sampel sedimen dikeringkan di Laboratorium menggunakan oven dengan suhu $70^{\circ} \mathrm{C}$ selama 48 jam. Pengeringan ini dilakukan untuk mengurangi kandungan air pada sedimen (berat sedimen tetap) (Peng et al., 2017)

b. Pengurangan Volume

Sampel sedimen hasil pengeringan akan disaring pada ayakan. Saringan atau ayakan yang digunakan mempunyai ukuran pori $5 \mathrm{~mm}$ dengan diameter ayakan yaitu $20 \mathrm{~cm}$ (Kyoung et al., 2015). Pengayakan atau penyaringan ini dilakukan untuk mengurangi volume sedimen serta untuk memilah sedimen makro dan mengidentifikasi sedimen mikro $\leq 5 \mathrm{~mm}$ (Reza \& Hermawan, 2018).

c. Pemisahan densitas

Tahap pemisahan densitas dilakukan dengan menimbang 100 gr sedimen kering dan disuspensikan dengan larutan $\mathrm{NaCl}$ Jenuh 300 $\mathrm{ml}$ pada gelas kimia $500 \mathrm{ml}$, kemudian diaduk dengan menggunakan batang pengaduk bersih selama 2 menit (Peng et al., 2017). Setelah pengadukan, jenis plastik yang berukuran ringan akan mengapung dipermukaan, tipe mikroplastik umumnya adalah polystyrene, polyethylene, dan polypropylene (Sari et al., 2015).

\section{d. Penghitungan Menggunakan Mikroskop}

Larutan bagian atas suspense diambil menggunakan pipet ukur sebanyak $1 \mathrm{ml}$ kemudian diteteskan ke ruang kaca preparat (Sedgewick Rafter), selanjutnya. sampel mikroplastik diamati dibawah mikroskop binokuler (pembesaran lensa $4 \times / 0.10$ ) dengan pola "zig-zag" dari kiri ke kanan (Peng et al., 2017). Mikroplastik yang terlihat dihitung berdasarkan jenisnya yaitu fiber, film, fragmen, dan pellet (Lusher, 2013).

Hasil penelitian mikroplastik pada masing-masing stasiun lokasi penelitian akan dianalisis secara deskriptif dan ditampilkan dalam bentuk tabel dan gambar. Hasil pengamatan sampel sedimen di laboratorium akan dibedakan berdasarkan kategori jenis mikroplastik serta jumlah kandungan mikroplastik pada Perarian Teluk Kendari dan diolah pada aplikas Microsoft Excell dan analisis korelasi melalui software SPSS. Analisis Korelasi digunakan untuk menganalisis tingkat keeratan hubungan antar variabel (Susiana, 2014). Untuk variabel Y (dependent) adalah kelimpahan dan variabel X (independent) adalah arus dan suhu.

\section{Hasil dan Pembahasan}

Berdasarkan hasil penelitian dari empat stasiun, menunjukan bahwa tiga dari empat jenis mikroplastik ditemukan di Perairan Teluk Kendari. Tiga jenis mikroplastik yang ditemukan yaitu fragmen, film, fiber, dan jenis pellet tidak ditemukan. Hal ini disebabkan oleh kondisi Perairan Teluk Kendari masih memiliki nilai $\mathrm{pH}$ yang netral. Nilai $\mathrm{pH}$ yang diperoleh pada pengukuran di lokasi penelitian yaitu 6-7. Selain itu, jenis mikroplastik pellet mempunyai sifat selalu terikat dengan jenis logam lainnya dan hanya ditemukan diperairan yang mempunyai nilai $\mathrm{pH}$ tinggi. Sesuai dengan pernyataan (Holems et al., 2014), bahwa kelimpahan plastik pellet banyak ditemukan diperairan yang memiliki nilai $\mathrm{pH}$ yang tinggi, dengan nilai $\mathrm{pH}$ yang tinggi, maka pellet akan banyak terikat dengan jenis logam lainnya. Faktor lain juga dikarenakan belum adanya pabrik plastik di Kota Kendari sebagai sumber utama mikroplastik tipe pellet, sehingga mikroplastik jenis pellet tidak ditemukan pada penelitian ini. Menurut Kingfisher (2011), pellet merupakan mikroplastik primer yang langsung diproduksi oleh pabrik sebagai bahan baku pembuatan produk plastik. 


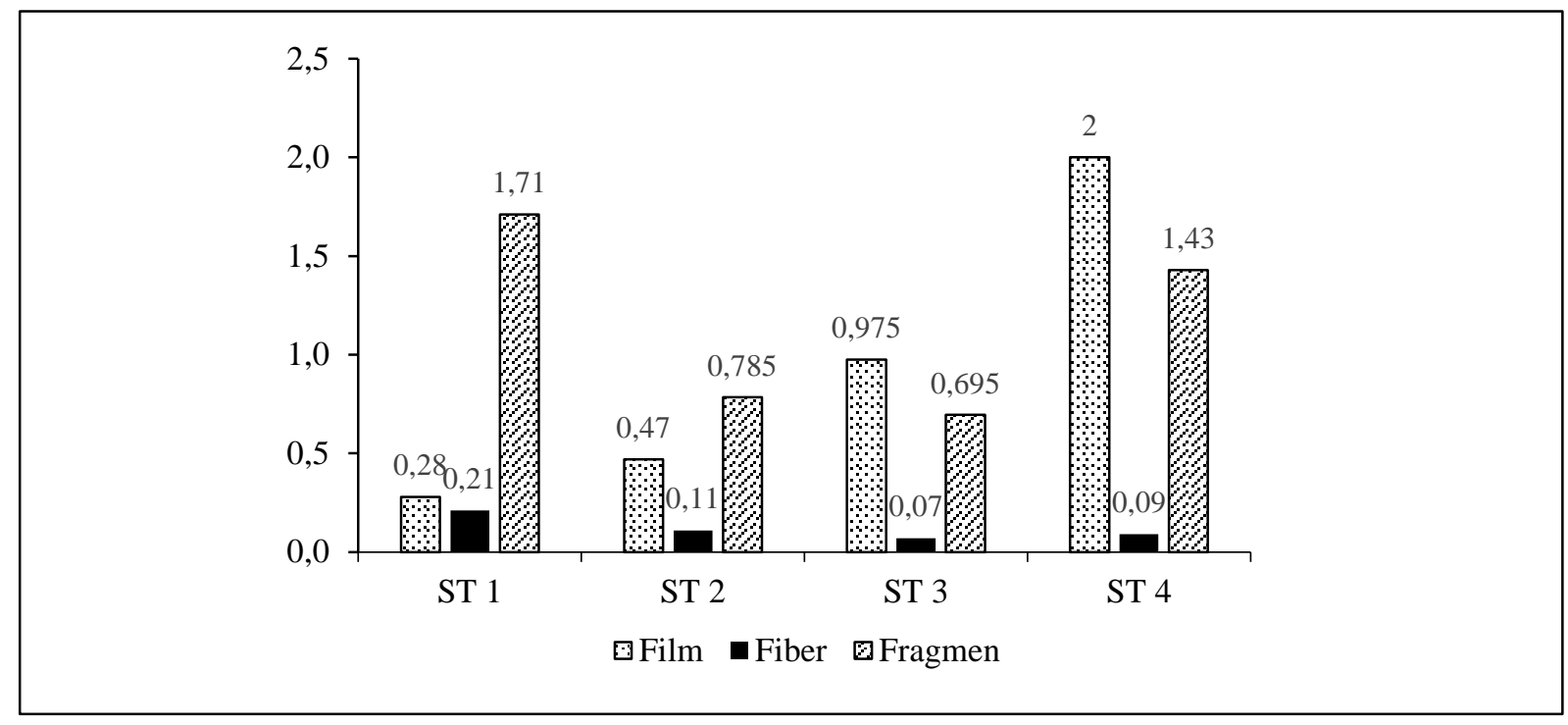

Gambar 2. Kelimpahan Jenis-jenis Mikroplastik yang ditemukan

Jenis mikroplastik paling sedikit yang ditemukan dalam penelitian ini adalah tipe fiber di Stasiun 3 (Pelabuhan Nusantara) yaitu 7 partikel/100 gr sedimen kering. Hal ini disebabkan karena lokasi pengambilan sampel sedimen di stasiun 3 (Pelabuhan Nusantara) merupakan tempat persinggahan kapal-kapal penumpang yang dominan menggunakan kantong plastik atau plastik kemasan, sehingga jarang ditemukan plastik jenis fiber. Fiber merupakan serat plastik memanjang dan berasal dari fragmentasi monofilament jaring ikan, tali dan kain sintetis (Sari et al., 2015). Mikroplastik pada stasiun menunjukan bahwa tipe yang paling tinggi adalah tipe fragmen yaitu 171 partikel/100 gr sedimen kering, hal ini dikarenakan lokasi pengambilan sampel sedimen, daerah aliran Sungai Wanggu berada pada daerah pemukiman penduduk, tambak dan areal pertanian. Banyaknya aktifitas pada daerah tersebut menjadi besar kemungkinan terjadi pembuangan sampah terutama sampah plastik di tepi Sungai Wanggu dan mengalir ke laut atau ke Perairan Teluk Kendari.

Tingginya nilai kelimpahan mikroplastik tipe fragmen sesuai dengan pernyataan Peng et al., (2017), masukan sungai perkotaan merupakan faktor utama untuk mikroplastik memasuki laut. Kelimpahan jenis fragmen yang banyak diakibatkan jumlah sampah yang dominan ditepi sunggai adalah botol-botol plastik dan limbah plastik rumah tangga laiinya yang merupakan sumber dari mikroplastik tipe fragmen. Limbah plastik jenis polypropylene yang berukuran makro akan mengalami fragmentasi dan pengecilan ukuran selama mengalir disungai dan menjadi sampah mikroplastik bertipe fragmen (Hidalgo-Ruz et al., 2012).

Mikroplastik yang paling sedikit ditemukan pada stasiun 1 adalah tipe fiber dengan nilai kelimpahan 21 partikel/100 gr sedimen kering. Hal ini disebabkan oleh kurangnya sumber sampah jenis fiber disekitaran sungai, sesuai dengan pernyataan Nur (2016) bahwa jenis fiber paling banyak ditemukan disekitaran perahu nelayan yang sebagai sumber adanya alat tangkap seperti jaring ikan dan alat pancing.

Stasiun 2 (Pemukiman), ditemukan jenis mikroplastik yang paling banyak adalah tipe fragmen dengan 78.5 partikel/100 gr sedimen kering, sedangkan untuk jenis mikroplastik yang paling sedikit adalah tipe fiber yaitu 11 partikel/100 gr sedimen kering.

Tipe mikroplastik jenis film merupakan jenis mikroplastik yang paling banyak ditemukan, jenis film banyak ditemukan di Stasiun 4 (PPS Kendari) yaitu 200 partikel/100 gr sedimen kering. Hal tersebut dikarenakan pada stasiun 4 memiliki arus yang cepat dibandingkan dengan arus di stasiun lainnya $(0,179 \mathrm{~m} / \mathrm{s})$, sehingga menyebabkan sumber mikroplastik bertipe film seperti kantong-kantong plastik dan kemasan makanan, banyak berserakan didepan dan disamping PPS Kendari. Mardiansyah (2018) menyebutkan bahwa distribusi dan sampah jenis kantong plastik, plastik sabun dan kertas banyak ditemukan di perairan berarus deras dan dalam. Menurut Kingfisher (2011), film merupakan polimer plastik sekunder yang berasal dari fragmentasi kantong plastik, plastik 
kemasan dan memiliki densitas rendah sehingga lebih mudah ditransportasikan.

Parameter lingkungan lainnya yang mempengaruhi proses degradasi plastik ialah suhu perairan. Nilai suhu perarian yang didapatkan pada pengukuran di stasiun 1,2,3 dan 4 yaitu 27 0C, 300C, 300C dan 310C. Nilai suhu perairan disetiap lokasi penelitian menunjukan bahwa, semakin tinggi suhu perarian maka semakin tinggi pula nilai kelimpahan mikroplastik pada suatu perarian. Hal ini sesuai dengan pernyataan Barnes (2009) bahwa, kerusakan aksi mekanis dari plastik semakin diperburuk oleh degradasi akibat sinar matahari (foto degradasi), degradasi akibat suhu perairan (degradasi termal) dan degradasi akibat makhluk hidup (biodegradasi), hal inilah yang menyebabkan banyak ditemukannya mikroplastik.

Nilai parameter lingkungan yang diambil pada penelitian ini ada dua parameter yaitu nilai arus dan suhu. Dimana arus dan suhu merupakan faktor lngkungan yang paling berpengaruh terhadap keberadaan mikroplastik pada sedimen.

Tabel 1. Parameter Lingkungan Perairan Teluk Kendari

\begin{tabular}{ccc}
\hline \multirow{2}{*}{ Stasiun } & \multicolumn{2}{c}{ Parameter Fisika Kimia Perairan } \\
\cline { 2 - 3 } & Arus $(\mathrm{m} /$ detik) & Suhu $\left({ }^{\circ} \mathrm{C}\right)$ \\
\hline 1 & 0.083 & 27 \\
2 & 0.027 & 30 \\
3 & 0.131 & 30 \\
4 & 0.179 & 31 \\
\hline
\end{tabular}

Banyaknya tipe fragmen yang didapatkan di stasiun 2, dikarenakan limbah atau sampah buangan masyarakat diarea pemukiman paling banyak adalah sampah rumah tangga. Sampah merupakan konsekuensi dari adanya aktifitas manusia, setiap aktifitas manusia pasti menghasilkan buangan atau sampah. Jumlah atau volume sampah sebanding dengan tingkat konsumsi terhadap barang atau material yang digunakan sehari-hari. Sari (2015) mengatakan bahwa, jenis sampah atau material buangan limbah rumah tangga adalah sumber yang paling besar adanya jenis mikroplastik bertipe fragmen.

Pada stasiun 3 (Pelabuhan Nusantara) ditemukan jenis mikroplastik yang paling banyak adalah tipe film yaitu 97.5 partikel/100 gr sedimen kering, sedangkan jenis mikroplastik yang paling sedikt ditemukan adalah jenis fiber dengan jumlah 7 partikel/100 gr sedimen kering (Gambar 3).

Tingginya tipe film yang ditemukan di stasiun 3 disebabkan oleh bertambahnya jumlah penumpang dan pengunjung di Pelabuhan Nusantara Kendari memberikan pengaruh terhadap bertambahnya sampah hasil konsumsi. Sampah yang paling banyak ditemukan diarea pelabuhan adalah sampah plastik seperti plastik kemasan makanan dan kemasan jenis kantong lainnya. Kemasan makanan dan kantongkantong plastik merupakan sumber adanya mikroplastik bertipe film. Menurut Sari (2015), sampah yang paling banyak ditemukan di pantai dan pelabuhan adalah sampah plastik kemasan dan kantong pembungkus lainnya yang merupakan wadah praktis dari pengunung pantai atau pengguna transportasi laut. Film merupakan polimer plastik sekunder yang berasal dari fragmentasi kantong plastik atau plastik kemasan (Kingfisher (2011)

Jenis mikroplastik yang paling banyak ditemukan di stasiun 4 (Pelabuahan Perikanan Samudra Kendari) adalah tipe film dengan jemlah 200 partkel/ 100 gr sedimen kering (Gambar 3). Sedangkan jenis mikroplastik yang paling sedikit ditemukan adalah jenis fiber dengan jumlah 9 partikel/100 gr sampel sedimen kering (Gambar 3).

Tipe mikroplastik jenis film merupakan jenis mikroplastik yang paling banyak ditemukan, jenis film banyak ditemukan di Stasiun 4 (PPS Kendari) yaitu 200 partikel/100 gr sedimen kering. Hal tersebut dikarenakan pada stasiun 4 memiliki arus yang deras $(0,179$ $\mathrm{m} / \mathrm{s}$ ) sehingga menyebabkan sumber mikroplastik bertipe film seperti kantongkantong plastik dan kemasan makanan, banyak berserakan didepan dan disamping PPS Kendari. Mardiansyah (2018) menyebutkan bahwa distribusi dan sampah jenis kantong plastik, plastik sabun dan kertas banyak ditemukan di perairan berarus deras dan dalam. Menurut Kingfisher (2011), film merupakan polimer plastik sekunder yang berasal dari fragmentasi kantong plastik, plastik kemasan dan memiliki densitas rendah sehingga lebih mudah ditransportasikan.

Berdasarkan jenisnya, persentase kelimpahan mikroplastik yang paling banyak ditemukan di Perairan Teluk Kendari adalah jenis fragmen dengan persentase $52 \%$, persentase kelimpahan terbanyak kedua adalah jenis film dengan persentase $42 \%$ dan yang 
terakhir adalah jenis fiber dengan presentase kelimpahan $6 \%$.

Hasil dari nilai persentase kelimpahan tersebut menunjukan bahwa, kelimpahan mikroplastik jenis fragmen tidak berbeda jauh dengan kelimpahan mikroplastik jenis film. Beda halnya dengan mikoplastik jenis fiber yang memiliki selisih nilai persentase kelimpahan jauh jika dibandingkan dengan jenis lainnya. Hal ini dikarenakan limbah buangan sampah plastik yang paling banyak ditemukan di Perairan Teluk Kendari adalah botol-botol plastik dan limbah plastik rumah tangga yang merupakan sumber dari mikrplastik tipe fragmen. Limbah plastik jenis polypropylene yang berukuran makro akan mengalami fragmentasi dan pengecilan ukuran selama mengalir disungai dan menjadi sampah mikroplastik bertipe fragmen (Hidalgo-Ruz et al., 2012).

Jenis sampah plastik lainnya yang banyak ditemukan di Perairan Teluk Kendari yaitu seperti kantong-kantong plastik atau kemasan plastik instan yang merupakan sumber dari mikroplastik jenis film. Menurut Kingfisher (2011), film merupakan polimer plastik sekunder yang berasal dari fragmentasi kantong plastik, plastik kemasan dan memiliki densitas rendah sehingga lebih mudah ditransportasikan.

Berdasarkan empat titik stasiun pengambilan sampel sedimen, persentase kelimpahan mikroplastik yang paling banyak ditemukan ada pada stasiun 4 dengan pesentase kelimpahan yaitu $40 \%$, kelimpahan terbanyak kedua ada pada stasiun 1 dengan nilai persentase kelimpahan yaitu $25 \%$, kelimpahan terbanyak ketiga ada pada stasiun 3 dengan nilai persentase kelimpahan yaitu $20 \%$ dan kelimpahan terbanyak yang terakhir yaitu pada stasiun 2 dengan nilai persentase kelimpahan $15 \%$,

Korelasi merupakan salah satu teknik analisis dalam statistik yang digunakan untuk mencari hubungan antara dua variabel yang bersifat kuantitatif. Hubungan dua variabel tersebut dapat terjadi karena adanya hubungan sebab akibat atau dapat pula terjadi karena kebetulan saja. Dua variabel dikatakan berkolerasi apabila perubahan pada variabel yang satu akan diikuti perubahan pada variabel yang lain secara teratur dengan arah yang sama (korelasi positif) atau berlawanan (korelasi negatif).

\section{a) Korelasi antara Arus dan Kelimpahan Mikroplastik.}

Berdasarkan hasil analisis korelasi yang dilakukan pada parameter lingkungan (arus) dengan kelimpahan mikroplastik, informasi yang didapatkan yaitu, pertama, menunjukan hubungan antara variabel kelimpahan dan arus dengan angka koefisien korelasi Pearson sebesar ,925 $(0,925)$. Angka tersebut mendekati 1 yang berarti korelasi antara arus dengan kelimpahan mikroplastik adalah sangat kuat.

Tabel 2. Korelasi Parameter Arus dan Kelimpahan Mikroplastik

\begin{tabular}{llrr}
\hline & & Kelimpahan & Arus \\
\hline Kelimpahan & Pearson Correlation & 1 & 0.925 \\
& Sig. (2-tailed) & & 0.075 \\
& $\mathrm{~N}$ & 4 & 4 \\
\hline Arus & Pearson Correlation & 0.925 & 1 \\
& Sig. (2-tailed) & 0.075 & \\
& $\mathrm{~N}$ & 4 & 4 \\
\hline
\end{tabular}

Tabel 3. Korelasi Parameter Suhu dan Kelimpahan Mikroplastik

\begin{tabular}{llcr}
\hline & & Kelimpahan & Suhu \\
\hline Kelimpahan & Pearson Correlation & 1 & 0.273 \\
& Sig. (2-tailed) & & 0.727 \\
& N & 4 & 4 \\
\hline Suhu & Pearson Correlation & 0.273 & 1 \\
& Sig. (2-tailed) & 0.727 & \\
& N & 4 & 4 \\
\hline
\end{tabular}


Kedua, signifikan kedua variabel sebesar ,075 (0,075) seperti yang diperlihatkan pada keterangan Sig. (2-tailed) (Tabel 5). Hubungan kedua variabel $0,075>0,05$ yang berarti hubungan kedua variabel signifikan. Hubungan kedua variabel dua arah (2-tailed) yang berarti dapat searah dan tidak searah. Ketiga, hasil korelasi antara parameter arus dan kelimpahan mikroplastik memiliki angka koefisien yang positif $(0,925)$ yang berarti kedua variabel berkorelasi searah. Artinya, jika nilai parameter arus naik maka nilai kelimpahan mikroplastik juga naik.

Hal ini menunjukan bahwa, parameter arus merupakan salah satu faktor yang sangat mempengaruhi proses mekanik dan penguraian plastik yang berukuran besar menjadi kepingankepingan plastik yang berukuran kecil $(\leq 5$ $\mathrm{mm})$. Sesuai dengan pernyataan Anthony et al., (2018) bahwa, faktor utama dalam pengangkutan partikel mikroplastik secara alami ialah arus perarian, dimana mikroplastik akan menumpuk lebih banyak pada sedimen perarian.

b). Korelasi antara Suhu dan Kelimpahan Mikroplastik

Berdasarkan hasil analisis korelasi yang dilakukan pada parameter lingkungan (suhu) dan kelimpahan mikroplastik (Tabel 6), informasi yang didapatkan menunjukan hubungan antara variabel suhu dan kelimpahan dengan angka koefisien korelasi Pearson sebesar ,273 (0,273). Angka tersebut hampir mendekati 0 yang berarti korelasi antara suhu dengan kelimpahan mikroplastik adalah lemah. Hal ini sesuai dengan standar pedoman hubungan korelasi antar variabel bahwa angka koefisien dengan kisaran 0,21-0,40 merupakan kategori korelasi lemah (Tri, 2014).

Hasil korelasi antara parameter suhu dan kelimpahan mikroplastik memiliki angka koefisien yang positif $(0,273)$ yang berarti kedua variabel berkorelasi searah. Artinya, nilai parameter suhu dan kelimpahan adalah searah akan tetapi dengan kategori korelasi lemah.

Faktor yang mempengaruhi lemahnya korelasi suhu dan kelimpahan mikroplastik disebabkan oleh nilai kelimpahan mikroplastik jenis fragmen yang didapatkan pada stasiun 1 (Gambar 3) paling banyak dibandingkan kelimpahan jenis fragmen di stasiun lainnya, yaitu dengan kelimpahan 1,71/gr sedimen. Hal tersebut memberikan pola distribusi kelimpahan mikroplastik yang tidak linear berdasarkan nilai suhu yang didapatkan pada setiap stasiun. Tinginya nilai kelimpahan pada stasiun 1 dikarenakan oleh lokasi pengambilan sampel sedimen (Muara Sungai Wanggu) merupakan daerah aliran sungai yang dipengaruhi oleh kegiatan antropogenik, karena letaknya yang dekat dengan pemukiman dan memiliki aktivitas tinggi yang berpotensi menghasilkan buangan sampah secara bebas ke lingkungan. Selain itu, adanya pengaruh perbedaan jenis dan ukuran substrat terhadap keberadaan mikroplastik dapat mempengaruhi besaran kelimpahan mikroplasti di sedimen. Adhyastri (2017) mengatakan bahwa, sedimen lunak memiliki potensi yang tinggi dalam menerap sampah plastik.

Suhu merupakan salah satu parameter yang sangat mempengaruhi jumlah kelimpahan mikroplastik disuatu perairan, sebagaimana pernyataan Barnes et al., (2009) bahwa kerusakan aksi mekanis dari plastik semakin diperburuk oleh degradasi akibat sinar matahari (fotodegradasi) dan degradasi akibat suhu perairan (degradasi termal), hal inilah yang menyebabkan banyaknya mikroplastik di temukan di perairan. Hal tersebut juga tidak terlepas dari sumber sampah plastik eksternal yang menjadi penyebab utama banyaknya sampah plastik diperairan. Sebagaimana Hidalgo-Ruz et al., (2012) menyatakan bahwa, ada 2 jenis mikroplastik yakni mikroplastik primer dan mikroplastik sekunder, dimana mikroplastik sekunder adalah mikroplastik yang berasal dari fragmentasi dan pengecilan ukuran plastik besar menjadi ukuran kecil.

\section{Kesimpulan}

Berdasarkan hasil penelitian maka didapatkan kesimpulan tentang kelimpahan mikroplastik pada sedimen di Perairan Teluk Kendari adalah sebagai berikut :

1. Jenis-jenis mikroplastik yang ditemukan pada sedimen di Perairan Teluk Kendari ada tiga jenis yaitu tipe fragmen, film dan fiber.

2. Mikroplastik yang paling banyak ditemukan pada sedimen berdasarkan jenis pada setiap stasiunnya adalah jenis film dengan kelimpahan 2 partikel/gr sedimen sedangkan kelimpahan terendah adalah jenis fiber yaitu $0.07 \mathrm{partikel/gr} \mathrm{sedimen.} \mathrm{Dengan} \mathrm{persentase}$ jenis kelimpahan mikroplastik paling tinggi secara keseluruhan yaitu fragmen (52\%), film $(42 \%)$ dan fiber (6\%). 
Daftar Pustaka

Adhyastry A.M. 2017. Kelimpahan Mikroplastik di Teluk Jakarta. Bogor Agricultural. IPB: Bogor

Anthony M.B., Crump P., Niven S.J., Teuten E., Tonkin A., Galloway T., Thompson R. 2018. Accumulation of Miroplastic on Shorelines Woldwide: Sources and Skins. Journal Environmental Science and Technology. Vol 45 (9175)

Barnes D.K.A., Galgani F., Thompson C.R. 2009. Accumulation and Fragmentation of Plastic Debris in Global Environments. Philosophical Transactions of The Royal Society. Vol 364

Boucher, J. and Friot D. 2017. Primary Microplastics in the Oceans: A Global Evaluation of Sources. Gland, Switzerland: IUCN. 43pp.

Carr A. 1987. Impact of Nondegradable Marine Debrish on the Ecology and Survival Outlook of Sea Turtles. Marine Pollutan Bulletin. Vol 18 (6)

Carr S.A., Liu J., \& Tesoro A.G. 2016. Transport and Fate of Microplastic Particels in Wastewater Treatment Plants. Water Research. Vol 91 (174182)

Chubarenko I., Bagaev A., Zobkov M., \& Esiukova E. 2016. On Some Physical and Dynamical Properties of Microplastic Particles in Marine Environment. Marine Pollutan Bulletin. Vol. 108 (1-2).

Hidalgo-Ruz, V., L. Gutow, R.C. Thompson, M. Thiel. 2012. Microplastics in the marine environment: a review of the methods used for identification and quantification. Environmental Science and Technology, 46:3060- 3075.

Kingfisher, J. 2011. Micro-plastic Debris Accumulation on Puget Sound Beaches. Port Townsend Marine Science Center [Internet]. Diakses pada tanggal 8 April 2015 pukul 16.56 WITA.

Kyoung Y.A., Hee S.H., Jang M., Myung G.H., Rani M., Lee J., Joon W.S. 2015. A Comprasion of Microscopic and Spectroscopic Identification Method for Analysis of Microplastics in Environmental Samples. Journal Marine Pollution Bulletin.

Lusher A.L. McHugh M., \& Thompson R.C. 2013. Occurrence of Microplastic in the Gastrointestinal Tract of Pelagic and
Demersal Fish from the English Channel. Marine Pollutan Bulletin. Vol 67 (1-2)

Mardiansyah Y.A., Bayu R.Z., \& Arif M.T. 2018. Distribusi dan Jenis Sampah Laut serta Hubungannya terhadap Ekosistem Terumbu Karang Pulau Pramuka, Panggang, Air, dan Kotok Besar di Kepulauan Seribu Jakarta. Majalah Ilmiah Biologi Biosfera. Vol 35 (2)

National Oceanic and Atmospheric Administration. 2013. Programmatic environmental assessment (PEA) for the NOAA Marine Debris Program (MDP). Maryland (US): NOAA. $168 \mathrm{p}$.

Ng K.L., \& Obbard J.P. 2006. Prevalence of Microplastic in Singapore's Coastal Marine Environment. Marine Pollutan Bulletin. Vol 52 (7) 761-767

Peng G., Zhu B., Yang D., Su L., Shi H., \& Li D. 2017. Microplastics in sediments of the Chanjian Estuary, China. Journal Environmental Pollution. Elsevier: China.

Putra A., Husrin S., Mutmainah H. 2017. Pola Sebarans Kualitas Air Berdasarkan Kesesuaian Baku Mutu untuk Biota Laut di Teluk Kendari Provinsi Sulawesi Tenggara. Maspari Journal. Vol 9 (1).

Reza M.C., E.M.Hernawan. 2018. Microplastics in Sumba Waters, East Nusa Tenggara. Journal Earth and Environmental Science. IOP Publishng.

Reza M.C. \& Wahyudi A.J. 2016. Microplastic in the Deep-Sea Sediment of Southwesternt Sumatran Waters. Journal Research Gate Indonesia. Vol. 41 (1)

Sari I.D., Aditya A.B., \& Ramadhan I.R. 2015. Distribusi Mikroplastik pada Sedimen di Muara Badak, Kabupaten Kutai Kartanegara. Journal Research Gate Indonesia. Vol 4 (3).

Tri A.B. 2014. Penggunaan SPSS dalam Statistik. Danisa Media: Yogyakarta.

Woodall L.C., Sanchez-Vidal A., Canals M., Paterson G.L.J., Coppock R., Sleight V., Thompson R.C. 2014. The Deep Sea is a Major Sink For Microplastic Debris. Royal Society Open Sience. Vol 1 (4).

Wright S.L., Thompson R.C., Galloway T.S. 2013. The Physical Impacts of Microplastic on Marine Organism: $A$ review. Environmantal Pollutan, 178: 483-492. 